\title{
A Model to Estimate the Amount of Primary Inoculum of Elsinoë ampelina
}

\author{
Odile Carisse and Annie Lefebvre, Agriculture and Agri-Food Canada, St-Jean-sur-Richelieu, Quebec, J3B 3E6, Canada
}

\begin{abstract}
Carisse, O., and Lefebvre, A. 2011. A model to estimate the amount of primary inoculum of Elsinoë ampelina. Plant Dis. 95:1167-1171.

In Eastern Canada, anthracnose, caused by the fungus Elsinoё ampelina, is a serious disease on susceptible grape cultivars. In the absence of management tools, anthracnose management relies almost exclusively on fungicide applications programmed at fixed intervals. Therefore, a better understanding of the factors affecting primary inoculum release and abundance would help in the timing of the first fungicide applications. The temporal dynamics of airborne primary inoculum released from cane cankers were investigated from 2007 to 2010 . One to three times per week, starting in the first week of April, six 12-cmlong cane pieces were randomly selected from diseased canes that had overwintered on a vineyard floor. The concentration of E. ampelina conidia was expressed as the number of conidia per square millimeter of canker. In total, 27, 32, 33, and 118 samplings were conducted in 2007, 2008, 2009, and 2010, respectively, with the 118 samplings conducted on three sites at 49, 35, and 34 samplings for site 1, 2, and 3, respectively. Each year, the number of conidia per square millimeter of canker was expressed as the proportion of seasonal inoculum (PSI) at

the same site and analyzed as a function of degree-days (DD; base temperature $=0^{\circ} \mathrm{C}$ ) accumulated since 1 April (cumulative degreedays $[\mathrm{CDD}])$. The nonlinear sigmoid model in the form PSI $=$ $1.003 /\left(1+\mathrm{e}^{-((\mathrm{CDD}-566.133) / 139.204)}\right)$ provided adequate fit to the observed data $\left(P<0.0001, R^{2}=0.97\right)$. When the model was validated against independent data, the model adequately predicted PSI; however, reliability was improved by adding a "dry days" threshold of 6 days during which accumulation of DD is stopped. This study shows that primary inoculum of grape anthracnose is available early in the season before bud break; meaning that emerging leaves could be infected provided that weather conditions are favorable. The results also show that there is an overlap in the availability of primary and secondary inoculum, mainly during the period of rapid leaf growth, a situation that may explain the explosive nature of the disease. The results suggest that, on susceptible cultivars and when there is a history of anthracnose in the vineyard, a fungicide spray program should be initiated early in the season, as soon as leaves are present.
\end{abstract}

Anthracnose, also call bird's-eye rot, is a disease of European origin caused by the fungus Elsinoë ampelina Shear $(20,26)$. Historically, the disease has caused serious crop losses in Australia, and epidemics have been reported in New Zealand, India, China, Japan, Korea, South Africa, South America, the United States, and, more recently, Eastern Canada $(2,4,9,12,18,19,20,22,27,33)$. Although all cultivars of the genus Vitis are more or less susceptible to anthracnose, those of the species vinifera are generally highly susceptible $(13,21,23,32)$. Vines infected by E. ampelina exhibit delayed development and berry ripening. Severely infected vines have considerably smaller yields due to fruit rot and are less able to survive the winter. E. ampelina attacks all aboveground parts of the vine. On the leaves, the fungus causes small, circular black or brown spots. As the lesions mature, the centers drop out, giving the leaves a shot-hole appearance. On the petioles and canes, E. ampelina causes deep, elongated cankers with grayish centers and black edges. In some cases, the lesions are so numerous, so deep, or both that the cane breaks, causing total loss of production on that cane. Following severe infections, the leaves may shrivel and drop. Infected berries develop sunken spots with grayish centers and black edges; severely infected berries dry up and drop prematurely.

Most of what is known about the epidemiology of grape anthracnose is derived from research conducted in tropical grape-production areas such as India or New Zealand $(18,28)$. Hence, the complete life cycle of E. ampelina in northern climates is not known. The fungus is likely to overwinter as sclerotia formed in mummified berries and in cane cankers formed in the autumn when the cane tissue lignifies (9). Suhag and Grover (27) reported that, in the climate of North India, the fungus survives on diseased canes on the vine and on prunings left on the ground or buried within 3 to

Corresponding author: O. Carisse, E-mail: odile.carisse@agr.gc.ca

Accepted for publication 18 May 2011.

doi:10.1094/PDIS-11-10-0798

(C) 2011 The American Phytopathological Society
$5 \mathrm{~cm}$ of the soil surface. In New Zealand, canker-borne sclerotia, when buried in the soil, may remain viable for up to 5 years (3). E. ampelina may also overwinter in infected berries or leaves, although the main source of primary inoculum is cane cankers (27). In the spring, conidia and, occasionally, ascospores are formed on sclerotia and are released when temperatures reach $2^{\circ} \mathrm{C}$, provided that the sclerotia have been wetted for at least $24 \mathrm{~h}(1,20)$. Therefore, primary infection may occur as soon as susceptible tissues are present. Conidial infection can take place at temperatures ranging from 2 to $40^{\circ} \mathrm{C}$ but the optimum is between 30 and $35^{\circ} \mathrm{C}(3,28,31)$. Tissue wetness is required for infection and the necessary duration of wetness varies with temperature. At 30,21 , and $12^{\circ} \mathrm{C}$, the required durations of tissue wetness are $1.5,7$, and $10 \mathrm{~h}$, respectively (2). The incubation period is temperature-dependent; at 2, 12, and 16,C, symptoms will be expressed 14, 7, and 4 days after infection, respectively $(2,28)$. New conidia are produced within 1 to 5 days after lesions become visible, and infected leaves may produce conidia until early autumn (2). These characteristics explain at least in part why, in vineyards with a history of grape anthracnose, the disease progresses rapidly and may, under favorable conditions, cause complete vine defoliation (4).

In Eastern Canada, there are no fungicides registered specifically for grape anthracnose control, although some are expected to be registered soon. In other parts of the world where anthracnose is a problem, the disease is managed by means of dormant treatments with copper sulfate, lime sulfur, and Bordeaux mixture (9). Dormant sprays are generally followed by a fungicide spray program with 10- to 14-day intervals for at least 1 month after bud break (10). Protectant fungicides such as dithiocarbamates are effective against E. ampelina (10).

In Eastern Canada, especially the province of Quebec, grape anthracnose is a serious problem on susceptible cultivars, mainly 'Vandal Cliche', 'Marquette', and 'Traminette' (7). In response to anthracnose outbreaks, the lack of knowledge about anthracnose epidemiology in northern climates, and the absence of risk indicators, a research program on the epidemiology of E. ampelina was established at Agriculture and Agri-Food Canada. One of the objectives was to study the availability and abundance of primary 
inoculum and to estimate the length of the period during which primary inoculum is available (i.e., the risk for primary infections). It was hypothesized that conidia produced in cankers on infected canes are the most important source of primary inoculum and that conidia production and release are influenced by temperature, meaning that degree-days (DD) are a good indicator of primary inoculum abundance and availability. DD models describing spore maturation or release have been developed for several fungal pathogens, including Venturia inaequalis, the causal agent of apple scab $(11,14,25)$; Stemphylium vesicarium, the causal agent of brown spot of pear (15); Erysiphe necator, causing grape powdery mildew (5); and Sclerotinia sclerotiorum, the causal agent of Sclerotinia stem rot of soybean (29). These models provide knowledge about when the spore release season begins, when it is likely to peak, and when it ends.

\section{Materials and Methods}

Data collection. Infected canes were collected in an unsprayed vineyard planted with the Vandal Cliche during the autumn seasons of 2006, 2007, 2008, and 2009. The canes were cut into 12-cmlong pieces and left to overwinter on the vineyard floor in cotton mesh bags at the Agriculture and Agri-Food Canada experimental farm in Frelighsburg, Quebec, Canada (longitude $72^{\circ} 11^{\prime} 0.73^{\prime \prime} \mathrm{W}$, latitude $45^{\circ} 5^{\prime} 43.32^{\prime \prime} \mathrm{N}$ ) (Table 1). In 2009, infected canes were collected in two commercial vineyards planted with Vandal Cliche located at Estrie County (longitude $72^{\circ} 51^{\prime} 35.28^{\prime \prime} \mathrm{W}$, latitude $45^{\circ} 2^{\prime} 40.16^{\prime \prime} \mathrm{N}$ ) and Québec County (longitude $71^{\circ} 3^{\prime} 48.47^{\prime \prime} \mathrm{W}$, latitude $46^{\circ} 56^{\prime} 9.68^{\prime \prime} \mathrm{N}$ ) (Table 1). In the spring, starting in the first week of April, six cane pieces were randomly selected one to three times per week from all the pieces and brought to the laboratory. Each cane piece was cut in smaller pieces that contained only one canker. The length and width of each canker was measured with a calliper. Each cane piece was put in $500 \mu \mathrm{l}$ of distilled water and agitated for $6 \mathrm{~h}$ at room temperature $\left(20 \pm 2^{\circ} \mathrm{C}\right)$. The cane piece was removed, $5 \mu \mathrm{l}$ of iodine was added, and the concentration of Elsinoe ampelina conidia was estimated with a hemacytometer. The conidia concentration was expressed as the number of conidia per square millimeter of canker. In total. 27, 32, 33, and 118 samplings, each one with six replicates, were conducted in 2007, 2008, 2009 , and 2010, respectively; the 118 samplings were conducted at three sites with 49,35 , and 34 samplings at site 1,2 , and 3 , respectively.

Model development and validation. Each year at each site, the number of conidia per square millimeter of canker was expressed as the proportion of seasonal inoculum (PSI), calculated as the number of conidia per square millimeter of canker on each sampling day divided by the seasonal total (mean of all replicates). Cumulative degree-days (CDD) were calculated by summing daily DD (in temperature base [Tbase] $0^{\circ} \mathrm{C}$ ) from 1 April. Data collected in 2007, 2008, and 2009 were used to develop the model for a total of 552 observations (92 sampling dates $\times$ six replicates). Data collected in 2010 at the three sites were used to validate the model for a total of 708 observations (118 samplings $\times$ six replicates). To describe the PSI as a function of DD, a nonlinear sigmoid model was used $(5,6)$ as follows:

$\mathrm{PSI}=a /\left(1+\mathrm{e}^{-((\mathrm{CDD}-b) / c)}\right), c \neq 0$ where PSI is the proportion of seasonal inoculum in conidia per square millimeter of canker, CDD is DD in Tbase $0^{\circ} \mathrm{C}$ accumulated from 1 April, $a$ is the upper asymptote, $b$ is the transition center parameter, and $c \times 2.1972$ is a transition width parameter. The estimates of model parameters were determined using the Marquardt iterative method of the NLIN procedure in SAS (version 9.1; SAS Institute, Inc., Cary, NC). For the purpose of measuring the appropriateness of the fitted model, error sums of squares (SSE), root mean square errors (RMSE), and coefficients of determination $\left(R^{2}\right)$ were considered. Analysis of residuals was also used as a model selection criterion that included normality and visual inspection of the distribution of residuals. The model was evaluated by performing a simple regression analysis between the predicted values and the corresponding observations as paired data (goodness-of-fit between predicted and observed values) with the data used to construct the model and the data collected in 2010 that were not used to construct the model. Analyses of these linear regressions were done by testing whether the intercept and the slope were significantly different from 0 and 1 , respectively (8). In addition, because the model was developed from data collected during "wet" seasons, wetness was not considered as a limiting factor. However, in 2010, prolonged periods of dry days were encountered. To adjust the predicted PSI for periods of dryness, dry-day thresholds of 4 and 6 days after which accumulation of DD ceased were compared with the unadjusted model. Unadjusted DD accumulation was calculated as described previously. A dry day was defined as day with less than $2 \mathrm{~mm}$ of rain measured (20). The adjusted DD accumulation was calculated as for the unadjusted model; however, DD during dry days were not considered after 4 and 6 consecutive dry days for dry-day thresholds of 4 and 6 days, respectively.

\section{Results}

The temporal pattern of E. ampelina conidia release was similar for the 3 years of data used to construct the model (Fig. 1). The first conidia were released during the first week of April, and conidia release peaks were reached on 15 June, 30 May, and 24 May in 2007, 2008, and 2009, respectively. The mean number of conidia per square millimeter of canker varied from one year to another, with averages of $18,136,14,833$, and 4,428 conidia $/ \mathrm{mm}^{2}$ of canker in 2007, 2008, and 2009, respectively. The last conidia were released on 30 July, 19 August, and 19 August in 2007, 2008, and 2009, respectively (Fig. 1). When the number of conidia per square millimeter of cankers was transformed to PSI and expressed as a function of CDD (Tbase $={ }^{\circ} \mathrm{C}$ ), the variation in PSI followed a sigmoid pattern (Fig. 2). Hence, the nonlinear sigmoid model provided adequate fit to the observed data, as follows:

PSI $=1.003 /\left(1+\mathrm{e}^{-((\mathrm{CDD}-566.133) / 139.204)}\right)$

where the standard errors of the parameter estimates were 0.0050, 2.9043 , and 3.4315 for $a, b$, and $c$, respectively. The regression of the predicted values against the observed values was significant $(P$ $\left.<0.0001, R^{2}=0.98\right)$. The intercept was -0.009 , which was not significantly different from $0(P=0.4548)$, and the slope was 1.010, which was not significantly different from $1(P<0.3135)$.

In 2010, the temporal pattern of E. ampelina conidia release was similar for the cankers collected at site 1 (Frelighsburg) (Fig. 3A)

Table 1. Description of the vineyards in Quebec, Canada, surveyed for release of conidia of Elsinoë ampelina

\begin{tabular}{|c|c|c|c|}
\hline Vineyard location & Frelighsburg & Estrie & Québec \\
\hline Planted in & 2002 & 2003 & 1997 \\
\hline Planting density (vines/ha) & 2,222 & 2,400 & 2,440 \\
\hline Trellising systems & Vertical trellis & Geneva double curtain & Geneva double curtain \\
\hline Pruning practices ${ }^{\mathrm{a}}$ & Hillier & Hillier & Hillier \\
\hline Budbreak reached on ${ }^{\mathrm{a}}$ & 6 May & 14 May & 20 May \\
\hline Bloom reached on ${ }^{\mathrm{a}}$ & 17 June & 20 June & 26 June \\
\hline Veraison reached on ${ }^{\mathrm{a}}$ & 28 July & 5 August & 12 August \\
\hline Harvest reached on ${ }^{\mathrm{a}}$ & 15 September & 15 September & 25 September \\
\hline
\end{tabular}

${ }^{a}$ Date at which $50 \%$ of the vines reached the growth stage. 
and site 2 (Estrie) (Fig. 3B) and showed a slight delay for the cankers collected at site 3 (Île d'Orléans) (Fig. 3C). At the three sites, the first conidia were released during the first week of April and conidia release peaks were reached on 31 May, 28 May, and 30 May at sites 1,2, and 3, respectively. The mean number of conidia per square millimeter of canker was lower than the previous years and varied from one site to another, with means of 1,899 (maximum of 9,525), 2,340 (maximum of 10,368), and 3,750 (maximum of 14,104 ) conidia $/ \mathrm{mm}^{2}$ of canker at site 1,2 , and 3 , respectively. The last conidia were released on 1 August, 10 August, and 17 August at site 1, 2, and 3, respectively (Fig. 4). The PSI expressed as a function of CDD was similar for the three sites (Fig. 4). Overall, when the model was validated against independent data collected in 2010 at three sites, two of which were located in areas different from the area where the data used to develop the model were collected, the model adequately predicted PSI (Fig. 4). However, the model tended to overestimate the PSI at the three sites, especially when more than 750 DD were accumulated (Fig. 4). Nevertheless, there was a linear relationship between the observed PSI and the PSI values predicted using the model. The regression of the predicted values against the observed values was significant $\left(P<0.0001, R^{2}=0.97\right)$. The intercept was -0.0229 , which was not significantly different from $0(P=0.6578)$, and the slope was 1.0200 , which was not significantly different from $1(P<0.4413)$. The correlation between observed and predicted PSI values was slightly higher when the predicted values were calculated with the model adjusted for a dry-days threshold of 6 days than for predicted values calculated with the unadjusted model $\left(R^{2}=97\right.$ and 96, respectively). However, this correlation was lower when the
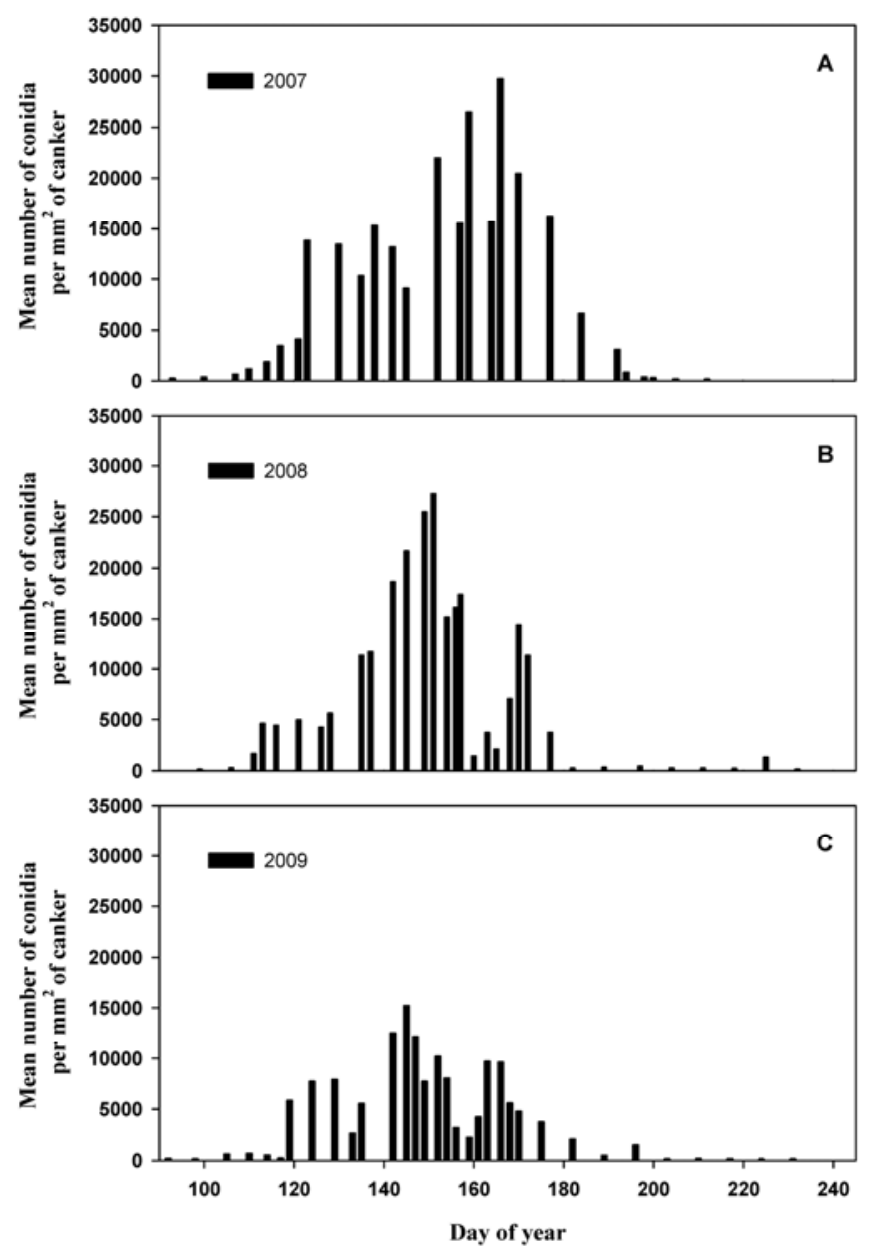

Fig. 1. Temporal dynamic of the mean number of conidia per square millimeter of canker caused by Elsinoë ampelina at the Agriculture and Agri-Food Canada experimental farm in Frelighsburg, Quebec, Canada. Bars represent the mean of six replicates collected in A, 2007; B, 2008; and C, 2009 . predicted values were calculated with the model adjusted for a drydays threshold of 4 days $\left(R^{2}=93\right.$; Fig. 5$)$.

\section{Discussion}

On susceptible cultivars, the amount of initial inoculum influences the severity of grape anthracnose in most grapevine-production areas with a humid spring (18). Given that E. ampelina can infect all aboveground parts and that young tissues are highly susceptible, major outbreaks occur when there is good synchronism between the availability of initial inoculum and the presence of susceptible host tissues (1). Because anthracnose has been reported as a serious disease mainly in warm-climate grapevine-production areas such as Florida, India, and Uruguay, it was expected that the disease would not become important for northern viticulture. However, the warm and rainy springs that occur in Eastern Canada are favorable to E. ampelina and, in the absence of knowledge on the effect of cold winters on the survival of the pathogen, it is difficult to measure how the cold winters of Eastern Canada will influence anthracnose establishment in that region's vineyards. Nevertheless, spring temperature is rarely a limiting factor for the production of conidia on overwintered canker-borne sclerotia, a process that occurs at temperatures of 2 to $40^{\circ} \mathrm{C}$, with optimal sporulation at $20^{\circ} \mathrm{C}$ $(1,9,20)$. Wetting of cane cankers is required for sporulation, and the minimum duration of wetting varies with temperature: the lower the temperature, the longer the required duration of wetting is $(1,9,20)$. However, Brook (2) reported that sclerotia that overwintered in the field can produce conidia in the absence of wetting.

With incubation periods varying from 13 to 14 days at $2^{\circ} \mathrm{C}$ and 3 to 4 days at $21^{\circ} \mathrm{C}$, the disease has the potential to progress rapidly $(2,20,28)$. Grape anthracnose is a polycyclic disease initiated by sclerotinia-borne conidia and spread by lesion-borne conidia. Although the stock of sclerotinia-borne conidia is determined by the number of cane cankers present the previous autumn, the lesionborne conidia are practically unlimited (2). On leaves infected early in the season, conidia will be produced continuously until late summer or early autumn; on cankers and newly infected leaves, however, conidia will be produced as long as the temperature is above $2^{\circ} \mathrm{C}(2)$.

Given that the amount of primary inoculum is determined mainly by the number of cane cankers present the previous autumn, most management programs for susceptible cultivars are based on sanitation practices, which consist of pruning and destroying diseased cane parts and eliminating wild grapes. On susceptible cultivars, however, sanitation practices generally do not suffice to control the disease, and fungicide sprays are needed. Because of the polycyclic nature of anthracnose, most fungicide

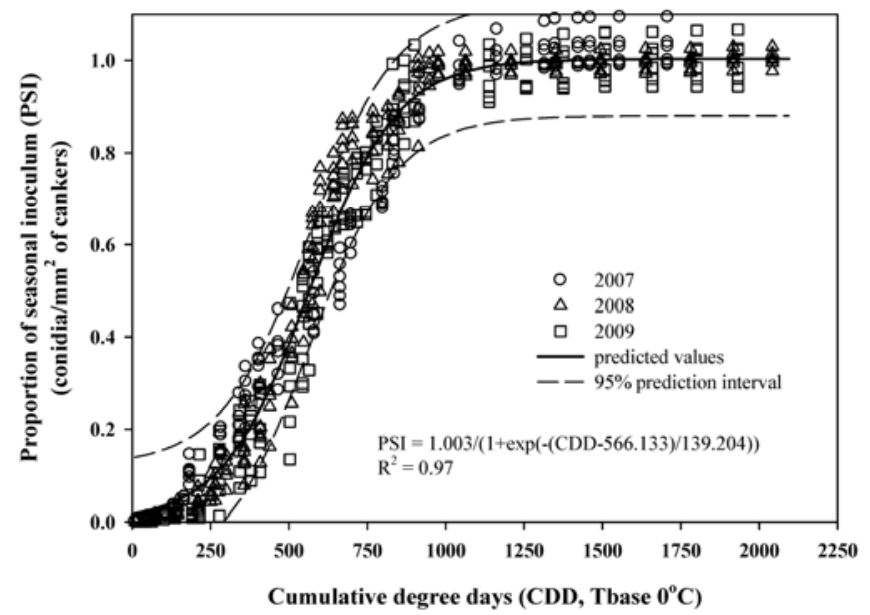

Fig. 2. Proportion of seasonal inoculum (PSI; in conidia per square millimeter of canker) as a function of cumulative degree-days (CDD; temperature base $0^{\circ} \mathrm{C}$ ). Symbols are the observations made in 2007, 2008, and 2009 and the solid and dashed lines represent the predicted values using equation 2 and the $95 \%$ prediction interval, respectively. 
spray programs are aimed at controlling infection caused by initial inoculum to avoid disease build-up caused by secondary inoculum. When initial infections are not properly controlled, the amount of fungicide required to prevent infected berries and reduced vine vigor may make the crop unprofitable (12).
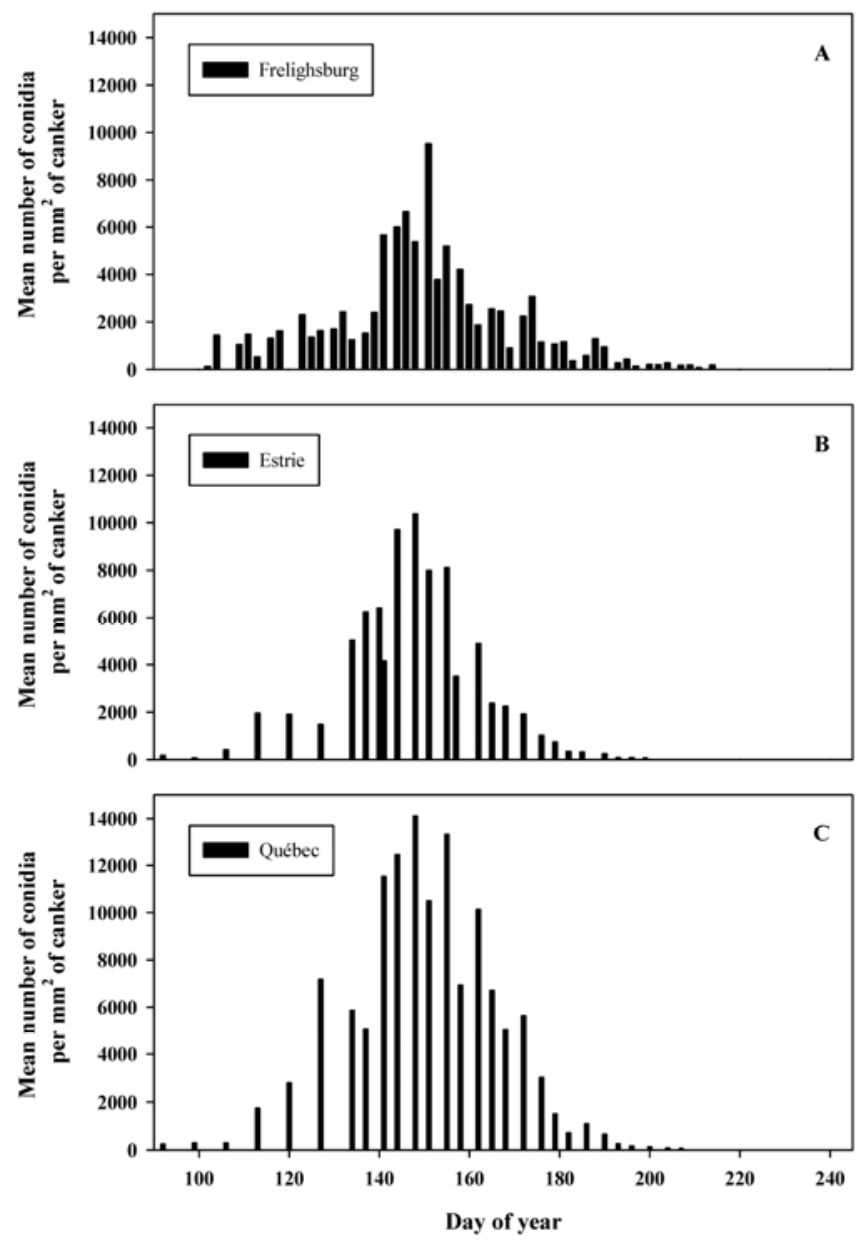

Fig. 3. Temporal dynamic of the mean number of conidia per square millimeter of canker caused by Elsinoë ampelina $\mathbf{A}$, at the Agriculture and Agri-Food Canada experimental farm in Frelighsburg and two commercial vineyards located in B, Estrie and C, Québec, Quebec, Canada. Bars represent the mean of six replicates collected in 2010.

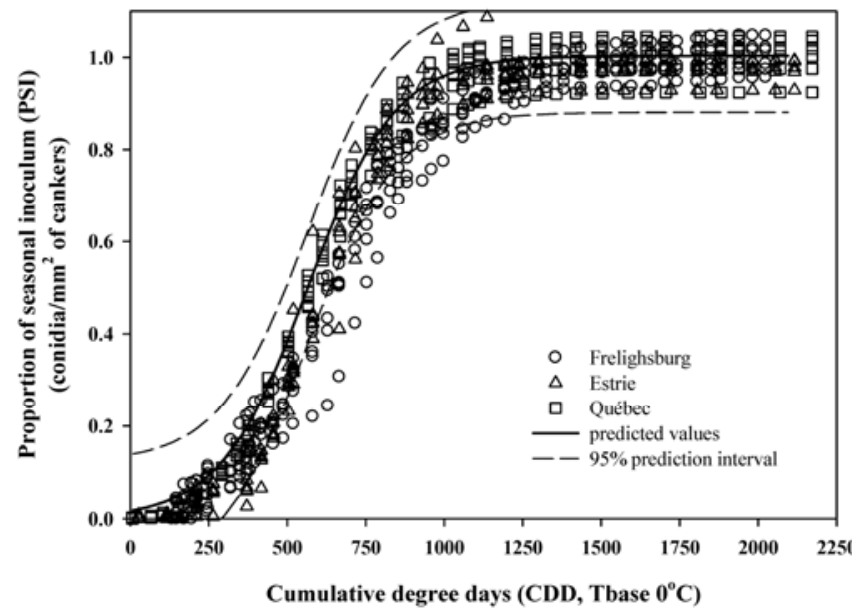

Fig. 4. Proportion of seasonal inoculum (PSI; in conidia per square millimeter of canker) as a function of cumulative degree-days (CDD; temperature base $0^{\circ} \mathrm{C}$ ). Symbols are the observations made in 2010 at three sites, and the solid and dashed lines represent the predicted values using equation 2 and the $95 \%$ prediction interval, respectively.
The present study was driven by the absence of tools to manage initial anthracnose infections and by the increasing variability in the weather conditions experienced during recent spring seasons in the province of Quebec, Canada. As a first step, the DD model developed in this study could be used by grapevine advisors and growers to determine more precisely when the first fungicide sprays should be applied and when the stock of initial inoculum is expected to be exhausted. In this study, it was assumed that the temperature is the main weather factor influencing the rate of conidial sporulation of sclerotia and that, under the conditions of Eastern Canada, moisture is not a limiting factor. A similar approach was used to forecast the availability and abundance of ascospores of $V$. inaequalis, the causal agent of apple scab, in various parts of the world, including the United States, Italy, New Zealand, and South Africa $(11,14,24,25)$. As is the case for most DD-based models describing the progress of the amount of initial inoculum, the relationship between the proportion of seasonal sclerotinia-borne inoculum of $E$. ampelina and CDD was described by a nonlinear sigmoid model. According to this model, minimum CDD values of 160,565 , and 970 DD $($ Tbase $=$ $0^{\circ} \mathrm{C}$ ) accumulated since 1 April are required for 5, 50, and $95 \%$ of the seasonal sclerotinia-borne conidia, respectively, to be produced.
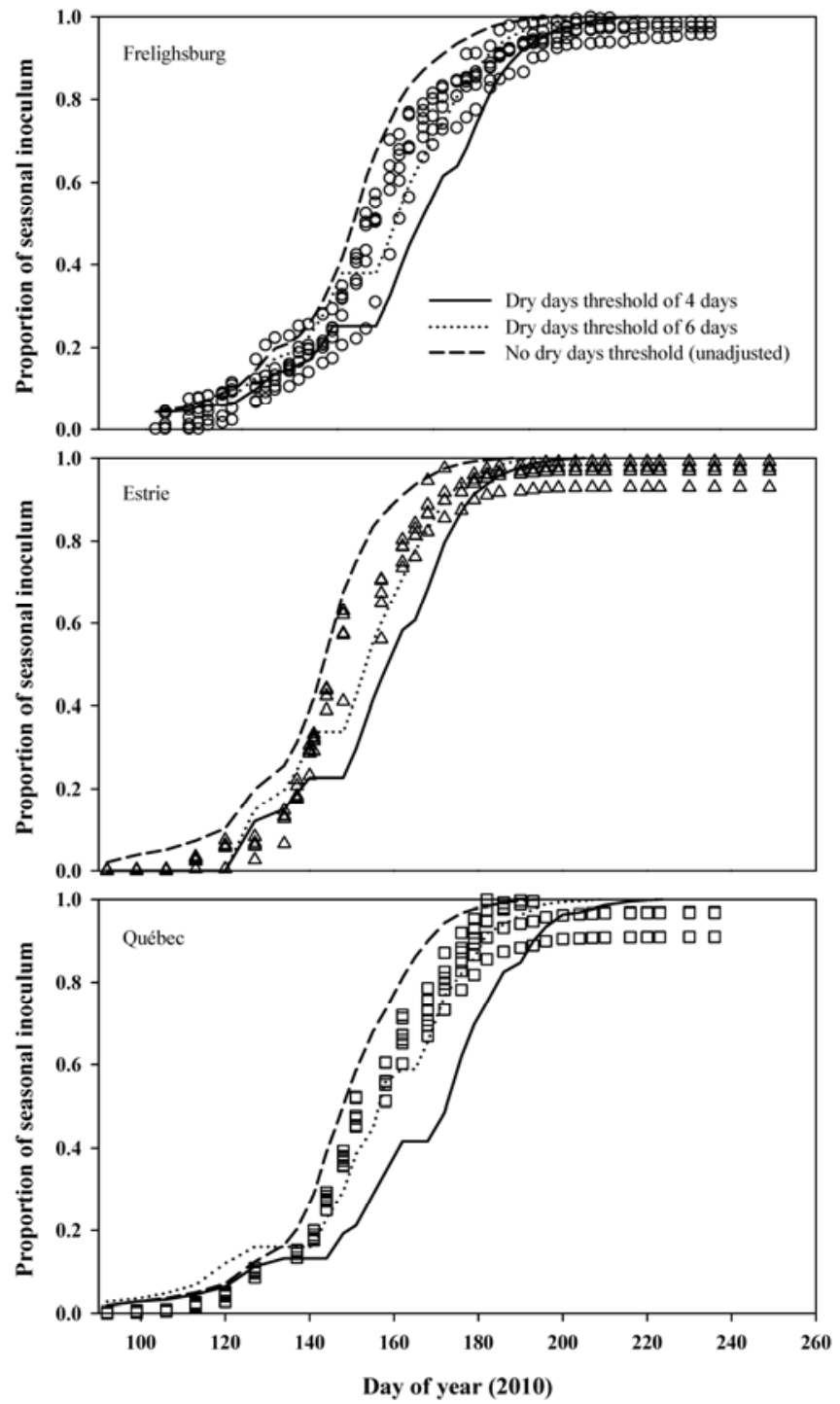

Fig. 5. Proportion of seasonal inoculum (PSI; in conidia per square millimeter of canker) predicted with the unadjusted model and with the model adjusted for drydays thresholds of 4 and 6 days and observed values at Frelighsburg, Estrie, and Québec in 2010. 
The use of forecasting models to estimate the proportion of initial inoculum based on DD accumulation requires that the same biofix be used to compute the CDD. For most DD-based models, the biofix is based either on a phenological state of the host, such as stage 7 of the E-L scale for grape powdery mildew (Erysiphe necator) (5) or the silver tip stage for apple scab (17), or on the date of $50 \%$ petal fall (30). To avoid sampling to determine the date at which the biofix is reached as well as error due to nonuniform growth of the host (i.e., all the plants are reaching the specific stage on the same date), some models are based on calendar dates (6). Nevertheless, DD-based models have proven to be useful tools to help in informed decision making regarding fungicide sprays (16). The model in the present study was developed with data collected from 2007 to 2009 at one location and validated with data collected in 2010 at three locations. Overall, most of the observations collected in 2010 fell within the $95 \%$ confidence interval. The good fit of the model could be explained by the influence of temperature on the maturation and release of inoculum and by the use of field data rather than controlled-conditions data to construct the model. By halting DD (Tbase $=0^{\circ} \mathrm{C}$ ) accumulation if six consecutive days without rain occurred, accuracy of the model was improved. This adjustment to the DD model will allow prediction of proportion of seasonal inoculum of E. ampelina during dry years.

The development of this model is one of the initial steps in the design of grape anthracnose management schemes. Considering the difficulties related to the management of anthracnose on susceptible cultivars, such a model should be used as part of an integrated grape disease management program and, ideally, be coupled with sanitation practices aimed at reducing initial inoculum as well as efficient fungicide sprays.

\section{Acknowledgments}

This work was financially supported by Agriculture and Agri-Food Canada. We thank D. Rolland for technical assistance.

\section{Literature Cited}

1. Anderson H. W. 1956. Pages 377-382 in: Diseases of Fruit Crops. McGrawHill, New York.

2. Brook, P. J. 1973. Epidemiology of grapevine anthracnose, caused by Elsinoe ampelina. N.Z. J. Agric. Res. 16:333-342.

3. Brook, P. J. 1992. Epidemiology of grapevine anthracnose and downy mildew in an Auckland, New Zealand vineyard. N.Z. J. Crop Hortic. Sci. 20:37-49.

4. Carisse, O. 2005. Outbreak of anthracnose caused by Elsinoe ampelina in vineyards in Quebec. (Abstr.) American Phytopathological Society, North Eastern Division.

5. Carisse, O., Bacon, R., Lefebvre, A., and Lessard, K. 2009. A degree-day model to initiate fungicide spray programs for management of grape powdery mildew (Erysiphe necator). Can. J. Plant Pathol. 31:186-194.

6. Carisse, O., Jobin, T., and Bourgeois, G. 2008. Predicting apple leaf emergence from degree-day accumulation during the primary scab period. Can. J. Plant Sci. 88:229-238.

7. Carisse, O., and Lefebvre, A. Evaluation of northern climate grape cultivars for their susceptibility to anthracnose caused by Elsinoe ampelina. Plant Health Progress. In press.

8. Dent, J. B., and Blackie, M. J. 1979. Systems Simulation in Agriculture. Applied Science Publishers Ltd., London.

9. Du Plessis, S. J. 1940. Anthracnose of vines and its control in South Africa.
Department of Agriculture, South Africa, Sci. Bull. No. 216.

10. Emmett, R. W., Creecy, H., and Blanch, E. 1981. Fungicide evaluation for control of grapevine black spot or anthracnose. Fungic. Nematicide Tests 36:40.

11. Gadoury, D. M., and MacHardy, W. E. 1982. A model to estimate the maturity of ascospores of Venturia inaequalis. Phytopathology 72:901-904

12. Hopkins, D. L. 1973. Fungicidal control of bunch grape diseases in Florida Proc. Fla. State Hortic. Soc. 86:329-333.

13. Hopkins, D. L., and Harris. J. W. 2000. A greenhouse method for screening grapevine seedlings for resistance to anthracnose. Hortscience 35:89-91.

14. James, J. R., and Sutton, T. B. 1982. A model for predicting ascospore maturation of Venturia inaequalis. Phytopathology 72:1081-1085.

15. Llorente, I., and Montesinos, E. 2004. Development and field evaluation of a model to estimate the maturity of pseudothecia of Pleospora allii on pear. Plant Dis. 88:215-219.

16. MacHardy, W. E. 1996. Apple Scab: Biology, Epidemiology, and Management. American Phytopathological Society, St. Paul, MN.

17. MacHardy, W. E., and Gadoury, D. M. 1985. Forecasting the seasonal maturation of ascospores of Venturia inaequalis. Phytopathology 75:381-385.

18. Magarey, R. D., Coffey, B. E., and Emmett, R. W. 1993. Anthracnose of grapevines, a review. Plant Prot. Q. 8:106-110.

19. Mazzei Patrone, L. 1950. Control of vine anthracnose. Rev. Appl. Mycol. 29:494.

20. Mirica, I. I. 1988. Anthracnose. Pages 18-19 in: Compendium of Grape Diseases. R. C. Pearson and A. C. Goheen, eds. American Phytopathological Society, St. Paul, MN.

21. Mortensen, J. A. 1981. Sources and inheritance of resistance to anthracnose in Vitis. J. Hered. 72:423-426.

22. Ozoe, S., Takuda, T., and Hirsawa, T. 1972. Studies on the ecology and control of black rot of grapevines. Bulletin of the Shimane Agricultural University. Rev. Plant Pathol. 55:356.

23. Rogers, D. J., and Mortensen, J. A. 1979. The native grape species of Florida. Proc. Fla. State Hortic. Soc. 92:286-289.

24. Rossi, V., Ponti, I., Marinelli, M., Giosus, S., and Bugiani, R. 2000. A new model estimating the seasonal pattern of air-borne ascospores on Venturia inaequalis (Cooke) Wint. in relation to weather conditions. J. Plant Pathol. 82:1125-4653.

25. Schwabe W. F. S., Jones, A. L., and van Blerk, E. 1989. Relation of degreeday accumulations to maturation of ascospores of Venturia inaequalis in South Africa. Phytophylactica 21:13-16.

26. Shear, C. L. 1929. The life history of Sphaceloma ampelinum de Bary. Phytopathology 19:673-679.

27. Suhag, L. S., and Grover, R. K. 1972. Overwintering and control of Elsinoe ampelina, the cause of grapevine anthracnose. In: Viticulture in the Tropics. K. Chadha, G. Randhowa, and R. Pal, eds. Horticultural Society of India.

28. Suhag, L. S., and Grover, R. K. 1977. Epidemiology of grapevine anthracnose caused by Sphaceloma ampelinum in north India. Indian Phytopathol. 35:526-528.

29. Sun, P., and Yang, X. B. 2000. Light, temperature, and moisture effects on apothecium production of Sclerotinia sclerotiorum. Plant Dis. 84:12871293 .

30. Sutton, T. B., James, J. R., and Nardacci, J. F. 1981. Evaluation of a New York ascospore maturity model for Venturia inaequalis in north Carolina. Phytopathology 71:1030-1032.

31. Virk, K., and Grover, R. 1979. Effect of thiophanate-methyl on growth and metabolic activity of Sphaceloma ampelinum. Indian Phytopathol. 32:529533.

32. Yun, H., K., Park, K.S., Rho, J. H., Choi, Y. J., and Kang, K. K. 2006. Evaluating the resistance of grapevines against anthracnose by pathogen inoculation, vineyard inspection, and bioassay with culture filtrate from Elsinoe ampelina. J. Am. Pomol. Soc. 60:97-103.

33. Zhang, B., and Huang, Y. 1990. A list of important plant diseases in China. Rev. Plant Pathol. 69:97-104. 